\title{
BIM E A GESTÃO INTEGRADA DE TERRITÓRIOS URBANOS SUSTENTÁVEIS: UM ESTUDO SOBRE O PLANEJAMENTO URBANO INTEGRADO E SUSTENTÁVEL NA CIDADE DE CAMPOS DOS GOYTACAZES - RJ1
}

\author{
BIM AND THE INTEGRATED MANAGEMENT OF SUSTAINABLE URBAN \\ AREAS \\ A STUDY ON INTEGRATED URBAN PLANNING AND SUSTAINABLE IN \\ THE CITY OF CAMPOS DOS GOYTACAZES - RJ
}

\author{
Zander Ribeiro Pereira Filho \\ Universidade Federal do Rio de Janeiro (UFRJ) \\ zander.filho@iff.edu.br \\ Eduardo Gonçalves Serra \\ Universidade Federal do Rio de Janeiro (UFRJ) \\ serra@poli.ufri.br
}

\begin{abstract}
Resumo
Responsável por mais de $80 \%$ da produção e exploração do petróleo nacional (OMPETRO, 2015) e impulsionada por grandes investimentos privados, a Região Norte Fluminense do estado do Rio de Janeiro, é elemento de grande importância na dinâmica de integração competitiva. Neste contexto regional, Campos dos Goytacazes, município com maior arrecadação de royalties do petróleo no Estado do Rio de Janeiro (ANP, 2010), apresenta dificuldades em administrar e aplicar estas compensações nas demandas do seu crescimento urbano. Diante das incertezas políticas e certeza da finitude deste recurso natural, este estudo busca entender se o planejamento urbano desta cidade atende de forma integrada as orientações necessárias para alcançar o seu desenvolvimento sustentável. Este trabalho é um resultado parcial da dissertação de mestrado do Programa de Engenharia Ambiental da UFRJ, tendo como objetivo exploratório a realização de uma pesquisa bibliográfica aplicada a um estudo de caso, com intuito de verificar como a plataforma BIM (Building Information Modeling) pode auxiliar a gestão pública do referido município na elaboração de propostas urbanas integradas e sustentáveis. Este estudo obteve como resultado parcial referências do uso da plataforma BIM na gestão de cidades e propostas de sua implementação em Campos - RJ.
\end{abstract}

Palavras-chave: Planejamento Urbano. BIM. Desenvolvimento Sustentável.

\begin{abstract}
Responsible for over $80 \%$ of production and exploitation of domestic oil (OMPETRO, 2015) and driven by large private investment, the Norte Fluminense region of the state of Rio de Janeiro, is an important element in the dynamics of competitive integration. In this regional context, Campos dos Goytacazes, municipality with greater collection of oil royalties in the State of Rio de Janeiro (ANP, 2010), presents difficulties in managing and applying those offsets to the demands of its urban growth. In the face of political uncertainty and certainty of finitude of this natural resource, this study seeks to understand if the urban planning of this city meets in an integrated manner the
\end{abstract}

${ }^{1}$ PEREIRA FILHO, Z. R.; SERRA, E. G. BIM e a gestão integrada de territórios urbanos sustentáveis: um estudo sobre o planejamento urbano integrado e sustentável na cidade de Campos dos Goytacazes - RJ. In: ENCONTRO BRASILEIRO DE TECNOLOGIA DE INFORMAÇÃO E COMUNICAÇÃO NA CONSTRUÇÃO, $7 .$, 2015, Recife. Anais... Porto Alegre: ANTAC, 2015. 
necessary guidance to achieve their sustainable development. This work is a partial result of the dissertation of the Environmental Engineering Program at UFRJ, as exploratory objective the realization of a literature search applied to a case study, in order to verify how BIM platform (Building Information Modeling) can help the public administration of this municipality in the development of integrated and sustainable urban proposals. This study had as partial result references of the use of BIM platform in the city management and proposals for its implementation in Campos - RJ.

Keywords: Urban Planning. BIM. Sustainable Development.

\section{INTRODUÇÃO}

Building Information Modeling (BIM) ou Modelagem da Informação da Construção, como é traduzido pela Associação Brasileira de Normas Técnicas (ABNT), é em síntese um método colaborativo da gestão integrada de informações, podendo ser entendido também como uma plataforma que se utiliza de um formato harmonizador na troca de dados (Figura 1), sendo assim, uma ferramenta poderosa para simular os impactos do planejamento urbano e criar iniciativas em ambientes construídos antes de sua execução. Do mesmo modo que os modelos virtuais ajudam a projetar e entender edifícios, este trabalho aponta para considerarmos a seguinte escala: a cidade.

Figura 1 - Plataforma BIM

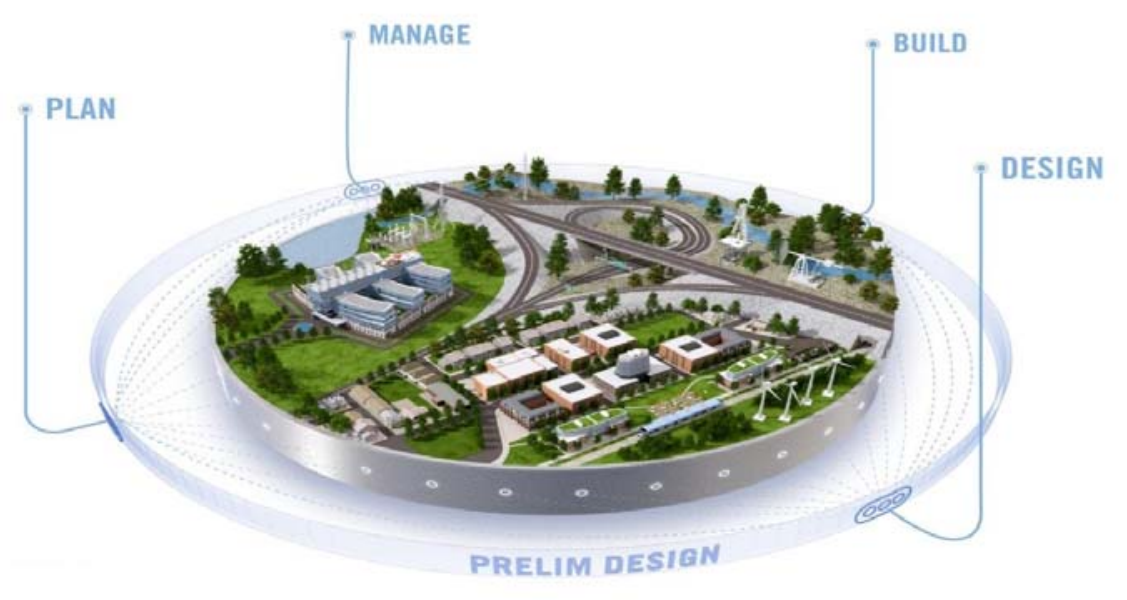

Fonte: Autodesk, 2013

Este estudo é resultado parcial da dissertação de mestrado do Programa de Engenharia Ambiental da UFRJ e busca contribuir com novas propostas de gestão e planejamento urbano em Campos dos Goytacazes - RJ através da plataforma BIM, visando atender de forma integrada suas ações urbanísticas a favor de seu desenvolvimento sustentável.

As pesquisas realizadas neste trabalho visam colaborar diretamente com o CIDAC, Centro de Informações e Dados de Campos, órgão municipal criado com o intuito de ser o gerenciador das informações produzidas sobre o município (CIDAC, 2015), demonstrando como a plataforma BIM pode ser utilizada em ações integradas que objetivem a eficiência na gestão e planejamento urbano no município.

Localizada a aproximadamente $279 \mathrm{~km}$ da capital Estadual do Rio de janeiro, Campos dos Goytacazes (Figura 2) possui números importantes na dinâmica econômica e espacial de seu Estado, sendo o município com a maior arrecadação de royalties do petróleo (ANP, 2010), além de ser o maior em extensão territorial (IBGE,2010). Diante desses números expressivos 
e assumindo o papel de líder na Região Norte Fluminense, Campos dos Goytacazes apresenta dificuldades em administrar e aplicar seus recursos financeiros de forma eficaz nas demandas do seu crescimento urbano.

Figura 2: Representação em destaque da cidade de Campos dos Goytacazes - RJ.

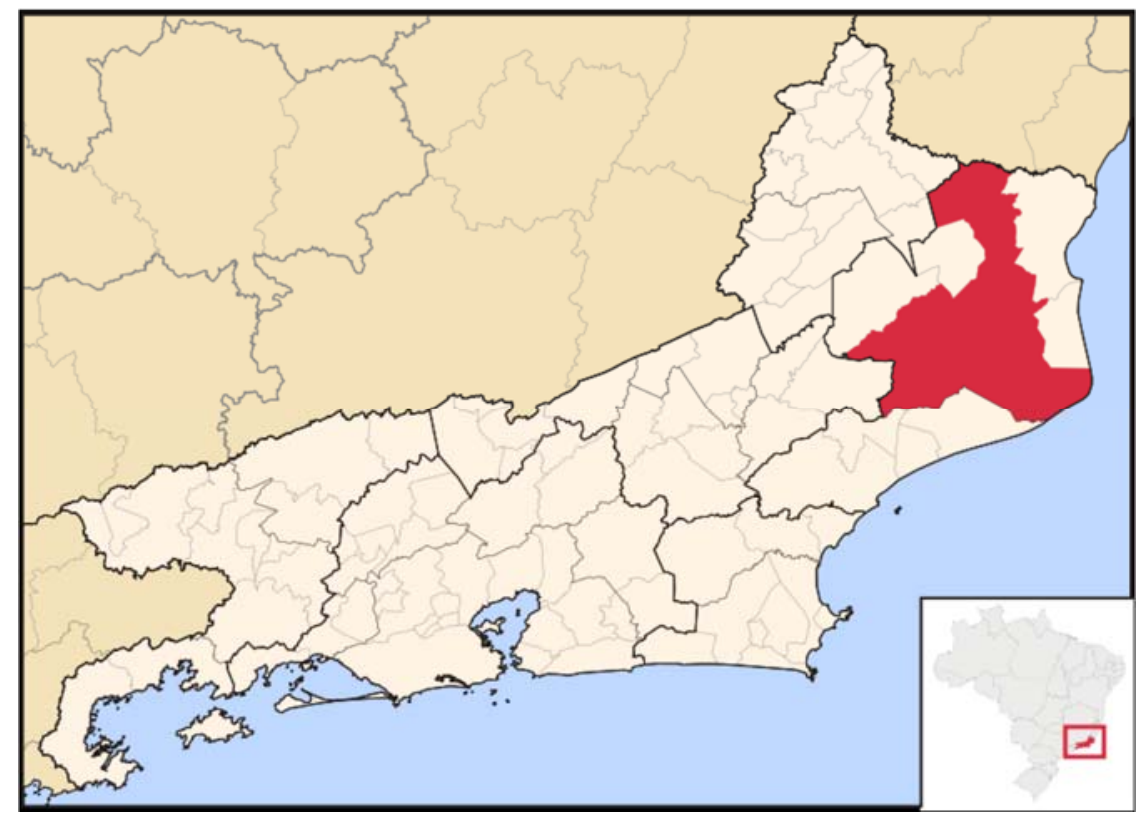

Fonte: Correa, 1999

Este trabalho será baseado no conceito de desenvolvimento sustentável descrito pela autora norueguesa Gro Harlem Brundtland. De acordo com Brundtland (1987), o desenvolvimento sustentável se define como "o desenvolvimento que satisfaz as necessidades do presente sem comprometer a capacidade das gerações futuras satisfazerem as suas próprias necessidades".

Tendo em vista a abrangência do tema enfocado e a complexidade tanto do ambiente urbano quanto do processo de planejamento e gestão que o envolve, foi necessário delimitar os aspectos observados e as variáveis a serem trabalhadas, optando-se por enfocar os pontos críticos para que o desenvolvimento fosse considerado sustentável. Desta forma, não foram incluídas questões de cultura organizacional, comportamento social e outros de natureza bastante subjetiva que poderão ser gradativamente incorporados em futuros trabalhos, a medida em que outros estudos forem sendo desenvolvidos.

Mais do que nunca, o uso do BIM ajuda a estabelecer um ponto de contato entre os vários participantes e disciplinas de um projeto. Isso poderá mudar os rumos do planejamento urbano sustentável nos próximos anos e ajudar a difundir esse tipo de tecnologia.

\section{OBJETIVO}

O objetivo geral deste trabalho é pesquisar como a plataforma BIM poderia ser utilizada na incorporação de orientações no desenvolvimento sustentável e planejamento urbano, com estudo de caso na cidade de Campos dos Goytacazes - RJ. Realizou-se a análise do cenário mundial, buscando referências de cidades que utilizaram o método colaborativo de gestão integrada usando a plataforma, com intuito de analisar os resultados obtidos. Através dessa análise, será possível propor e melhorar o processo decisório das equipes técnicas e dos gestores das políticas urbanas da administração municipal de forma a possibilitar o desenvolvimento sustentável. 


\section{METODOLOGIA}

A metodologia deste trabalho será baseada através de três tópicos principais. O primeiro deles é o estudo de caso realizado em Campos dos Goytacazes, com interesse de obter os dados históricos sobre a evolução urbana no município e analisar sua atual estrutura de gerenciamento de dados. O segundo tópico é a pesquisa bibliográfica, a fim de entender o conceito do desenvolvimento sustentável aliado ao conceito BIM e exemplificar seu uso no planejamento e na gestão de cidades. Por fim, análise dos dados obtidos, confrontando as informações encontradas para verificar as possibilidades de implementação da plataforma BIM na cidade estudada.

\section{O ESTUDO DE CASO}

Esta etapa será dividida em duas partes. A primeira analisará de forma resumida a evolução urbana em Campos dos Goytacazes ao longo de sua história, associando seus planos urbanísticos ao cenário econômico de cada época. A segunda parte pesquisará o CIDAC, Centro de Informações e Dados de Campos, órgão municipal responsável em promover soluções tecnológicas de informação e comunicação integradas e inovadoras para uma gestão pública eficiente e colaborativa (CIDAC, 2015).

\subsection{A evolução urbana em Campos dos Goytacazes}

Assumindo um lugar de importância na região norte e noroeste fluminense, a cidade de Campos desempenha um papel de liderança em toda a região. "os primeiros centros urbanos criados na região (...) foram Campos dos Goytacazes e São João da Barra (1676). Sem dúvida, a principal área de interesse de toda a Capitania foi o local onde hoje se localiza o Município de Campos dos Goytacazes(...)". (Faria, 2001, p.5). Sua importância econômica e política elevou, em 1835, da vila de São Salvador dos Campos dos Goytacazes à categoria de cidade. E, na hierarquia da incipiente rede urbana da região Norte Fluminense, Campos se configurava como o principal centro urbano, apresentando-se, ainda, como polo das atividades comerciais (Faria, 2003).

Quadro 1 - Principais intervenções urbanas em Campos dos Goytacazes

\begin{tabular}{|c|c|l|}
\hline Período/Ano & Cenário Econômico & \multicolumn{1}{c|}{ Intervenções Urbanas } \\
$\begin{array}{c}\text { Meados do } \\
\text { século XIX }\end{array}$ & $\begin{array}{c}\text { Auge do } \\
\text { Desenvolvimento } \\
\text { Açucareiro }\end{array}$ & $\begin{array}{l}\text { Primeiras iniciativas urbanas, construção de canais, } \\
\text { estradas de ferro, instalação de água e esgoto, } \\
\text { inclusive luz elétrica. Objetivando o fortalecimento do } \\
\text { comércio e a vontade em reforçar a importância da } \\
\text { cidade no processo de modernização brasileiro. }\end{array}$ \\
\hline 1902 & $\begin{array}{c}\text { Crise da economia do } \\
\text { Brasil Imperial e da } \\
\text { provincia do Rio de } \\
\text { Janeiro }\end{array}$ & $\begin{array}{l}\text { Plano Urbanístico de Saturnino de Brito, elaborado } \\
\text { com o objetivo de limpar a área central do município } \\
\text { que passou por um processo de crescimento urbano } \\
\text { devido as baixas atividades do plantio de açúcar. }\end{array}$ \\
\hline 1944 & $\begin{array}{c}\text { Crescimento do } \\
\text { Comercio e Serviços }\end{array}$ & $\begin{array}{l}\text { Plano Urbanístico Coimbra/Bueno contratado pelo } \\
\text { então Prefeito Salo Brand, buscou integrar a área } \\
\text { urbana central às áreas periféricas da cidade. }\end{array}$ \\
\hline 1979 & $\begin{array}{c}\text { Início das atividades } \\
\text { de Produção e } \\
\text { Exploração do } \\
\text { Petróleo }\end{array}$ & $\begin{array}{l}\text { PDUC (Plano de Desenvolvimento Urbanístico e } \\
\text { Territorial de Campos) principal objetivo: corrigir as } \\
\text { irregularidades vivenciadas no tecido urbano da } \\
\text { cidade e, principalmente, nas áreas menos } \\
\text { privilegiadas e carentes de infra-estrutura. }\end{array}$ \\
\hline
\end{tabular}




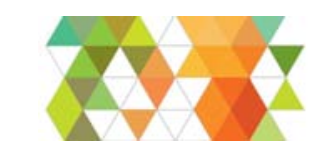

\section{TIC2015}

\begin{tabular}{|c|c|l|}
\hline $\begin{array}{c}1980 \text { a } \\
2000\end{array}$ & $\begin{array}{c}\text { Consolidação da E\&P } \\
\text { do Petróleo, } \\
\text { fortalecimendo do } \\
\text { comercio e serviços. }\end{array}$ & $\begin{array}{l}\text { A partir do descobrimento da Bacia de Petróleo de } \\
\text { Campos no início entre as década de 70/80, a } \\
\text { estabilidade econômica do país na década de 90, } \\
\text { Campos dos Goytacazes se tornou ainda mais } \\
\text { concentrada em seu núcleo urbano. }\end{array}$ \\
\hline $\begin{array}{c}2009 \text { a } 2015 \\
\text { Complexo Logístico }\end{array}$ & $\begin{array}{l}\text { Aumento de influencia do setor privados nas } \\
\text { Industrial Portuário do do } \\
\text { Açu }\end{array}$ & $\begin{array}{l}\text { decisões de políticas públicas e diretrizes } \\
\text { urbanísticas do município. }\end{array}$ \\
\hline
\end{tabular}

Fonte: Os Autores (2015)

De acordo com as informações anteriores (Quadro 1) pode-se afirmar que a evolução urbana (Figura 3) ocorrida em Campos dos Goytacazes - RJ estão relacionadas diretamente aos grandes surtos de desenvolvimento econômico. Percebe-se que os diversos planos urbanísticos elaborados para a cidade, por não terem sido implantados na sua integridade e por falta de intervenções concretas, não eliminaram os problemas existentes no espaço urbano. A cidade vive refém dos altos e baixos que a economia lhe proporciona, faltando, assim, uma gestão que consiga sustentá-la no períodos de escassez financeira.

Figura 3 - Evolução urbana na área central do município de Campos dos Goytacazes.

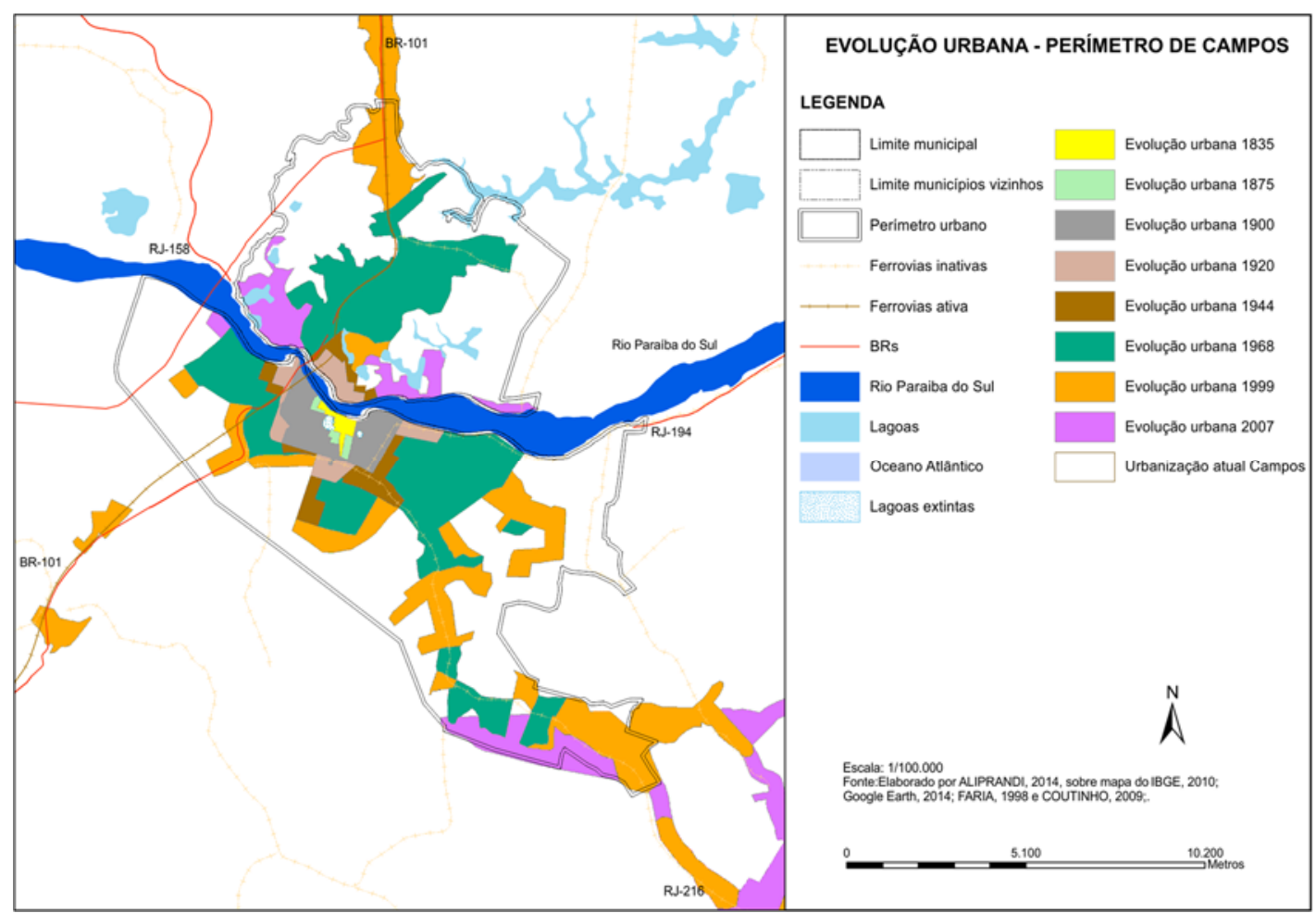

Fonte: ALIPRANDI, Danielly Cozer, 2014

\subsection{CIDAC - Centro de Informações e Dados de Campos}

O CIDAC, Centro de Informações e Dados de Campos, é um órgão público que atua na elaboração e implementação das políticas de Tecnologia da Comunicação e Informação na cidade. O órgão atua em conjunto com os demais setores públicos municipais na implantação e na modernização de sistemas informatizados de gestão da cidade de Campos dos Goytacazes, (CIDAC, 2015).

Através do estudo realizado dos diferentes órgãos municipais, o CIDAC apresenta em seus valores estratégicos afinidades com a proposta deste trabalho, como: 
- Normalização e integração dos Sistemas de Informação utilizados na Prefeitura Municipal de Campos dos Goytacazes;

- Melhoria na aquisição, tratamento e disponibilização de dados oriundos da Prefeitura Municipal de Campos dos Goytacazes;

- Melhoria das normas e políticas de aquisição e desenvolvimento de softwares;

- Aumento do nível de maturidade de Governança de TI, promovendo o alinhamento estratégico da TI com os objetivos de gestão da Prefeitura Municipal de Campos dos Goytacazes.

Por razões de compatibilidade com as recomendações deste trabalho, os resultados encontrados nesta pesquisa sobre o uso da plataforma BIM na gestão integrada de territórios urbanos sustentáveis, serão direcionados ao CIDAC, como propostas de implementação do BIM na gestão municipal em Campos - RJ.

\section{PESQUISA BIBLIOGRÁFICA}

Nesta parte do trabalho será apresentada referências do uso da plataforma BIM na gestão de territórios urbanos, destacando também o seu uso no desenvolvimento sustentável. Estas referências serão usadas como base nas propostas destinadas ao CIDAC.

\subsection{Seattle: um estudo de caso do modelo BIM na gestão integrada em cidades}

Um dos resultados desta pesquisa, é o projeto realizado no centro urbano de Seattle-EUA (Figura 4), que começou através do setor privado e ao longo do processo foi utilizado pela iniciativa pública como ferramenta de gestão integrada do município. Este modelo não representa apenas uma maquete virtual ilustrativa, nela se encontra todas as informações reais deste trecho da cidade como por exemplo suas linhas de infraestruturas urbanas.

Figura 4: Modelo BIM da cidade de Seattle - EUA

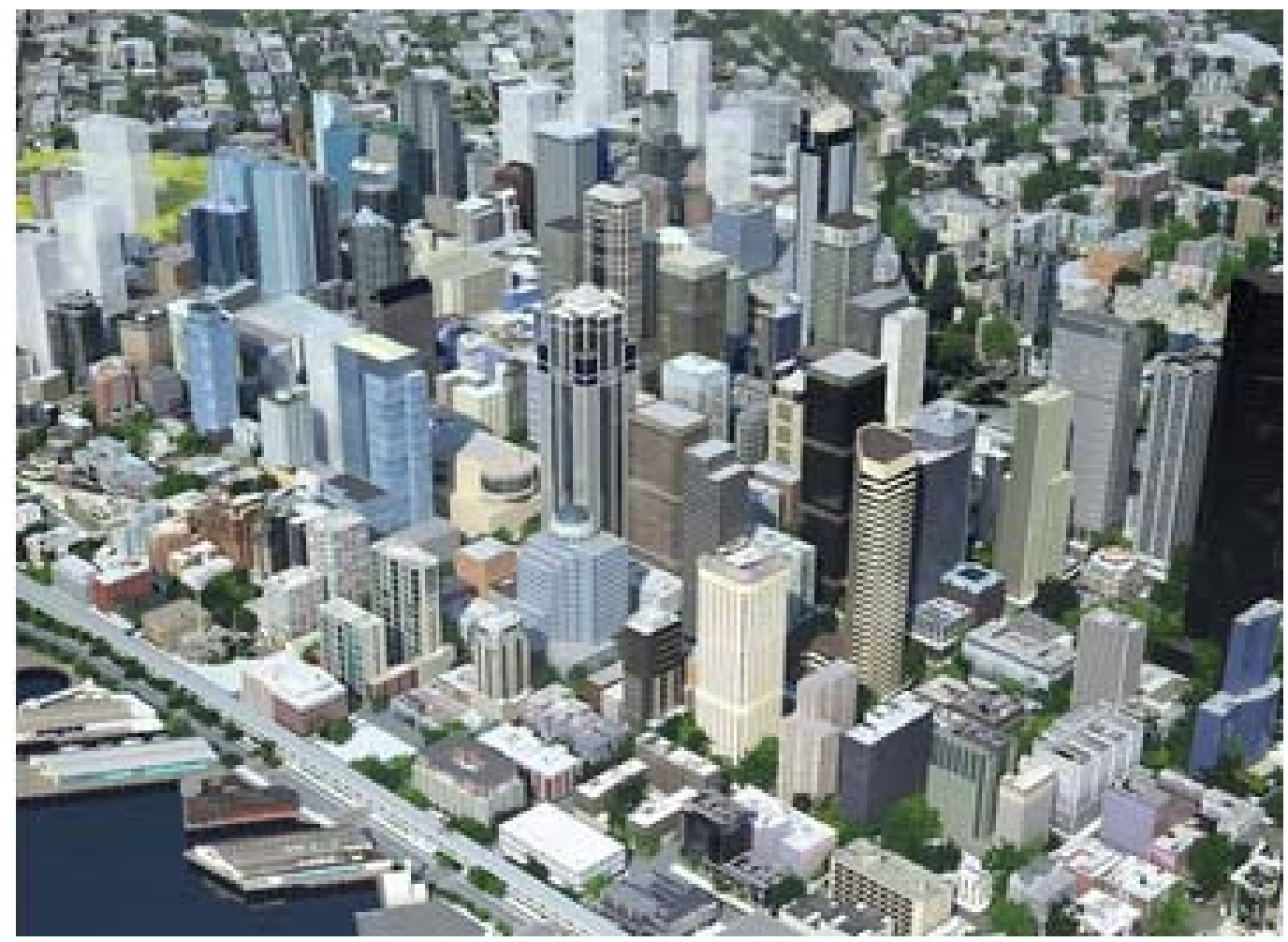

Fonte: Autodesk, 2013 
A cidade de Seattle-EUA, demonstra as vantagens da adoção de ferramentas que tenham em sua essência o controle dinâmico e colaborativo dos sistemas de infraestrutura (Figura 5). As premissas desta plataforma colaborativa visam atender as demandas destes sistemas, através das seguintes fases: projeto, execução, operação e desativação de redes urbanas.

Figura 5: Modelo BIM do túnel e linhas de infraestrutura na cidade de Seattle - EUA

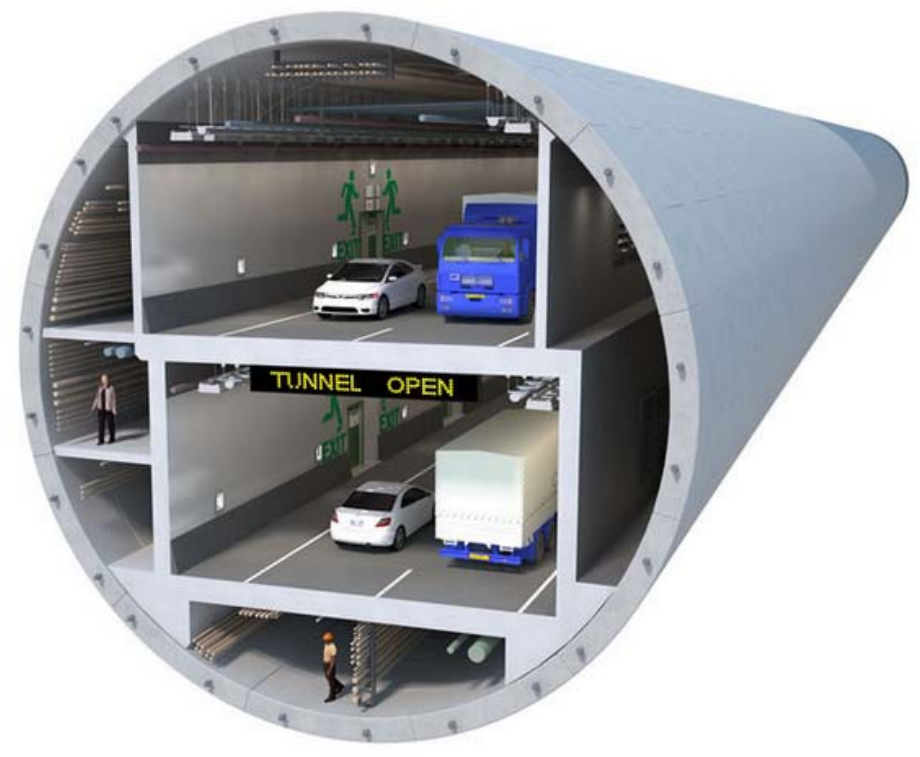

Fonte: Parsons Brinkerhoff, 2013

A fase de projeto, os softwares BIM permitem a criação de modelos e consequente visualização simultânea do projeto base e complementares, atribuindo maior credibilidade aos processos de revisão, verificação de interferências entre projetos e tomada de decisão.

$\mathrm{Na}$ fase de execução, o BIM traz benefícios e eficiência para as atividades referentes à administração do canteiro de obras, pessoas e matérias, o que resulta em maior agilidade na execução e consequente redução nos custos. Na fase de operação, o BIM ajuda na gerência da operação dos sistemas.

Por fim, a fase de desativação, embora os sistemas de infraestrutura tenham a característica de vida longa, aqueles materiais ou equipamentos pertencentes ao sistema que sofrem desativação devem receber um correto destino. Com um banco de dados completo sobre as características construtivas, facilmente se consegue identificar o local correto para a destinação daquele material, o que evita impactos ambientais.

\subsection{BIM como ferramenta no planejamento urbano}

De acordo com a National Building Information Modeling Standard (NBIMS, 2007), a plataforma BIM pode ser entendida em três níveis de abstração: produto, ferramenta (sistemas/software) e como processo. Nesta seção, entenderemos como resultado desta etapa, a análise da ferramenta BIM através do software Urban Canvas.

Para atender a necessidade de uma base de dados central que suprisse as demandas do planejamento urbano, o Professor Paul Waddell, do Departamento de Planeamento Regional e Urbano da Universidade de Berkeley criou um software chamado Urban Canvas. Este software trabalha no conceito BIM de integração das informações e visa um desenvolvimento colaborativo, permitindo aos urbanistas trabalharem em equipe no processo de modelação das cidades. Neste âmbito, o programa permite a partilha e tratamento de dados urbanísticos de múltiplas fontes. 

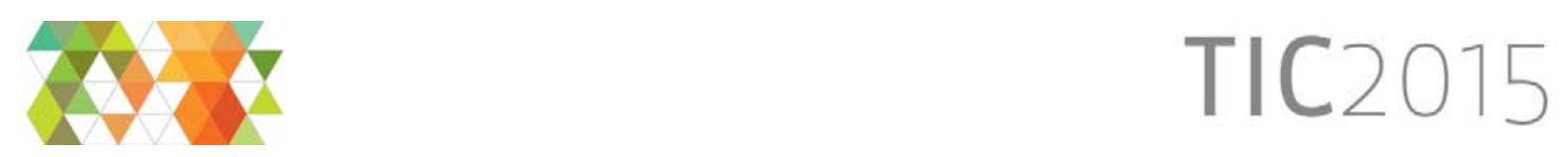

Figura 6: Imagem ilustrativa do uso do software da autodesk, UrbanCanvas

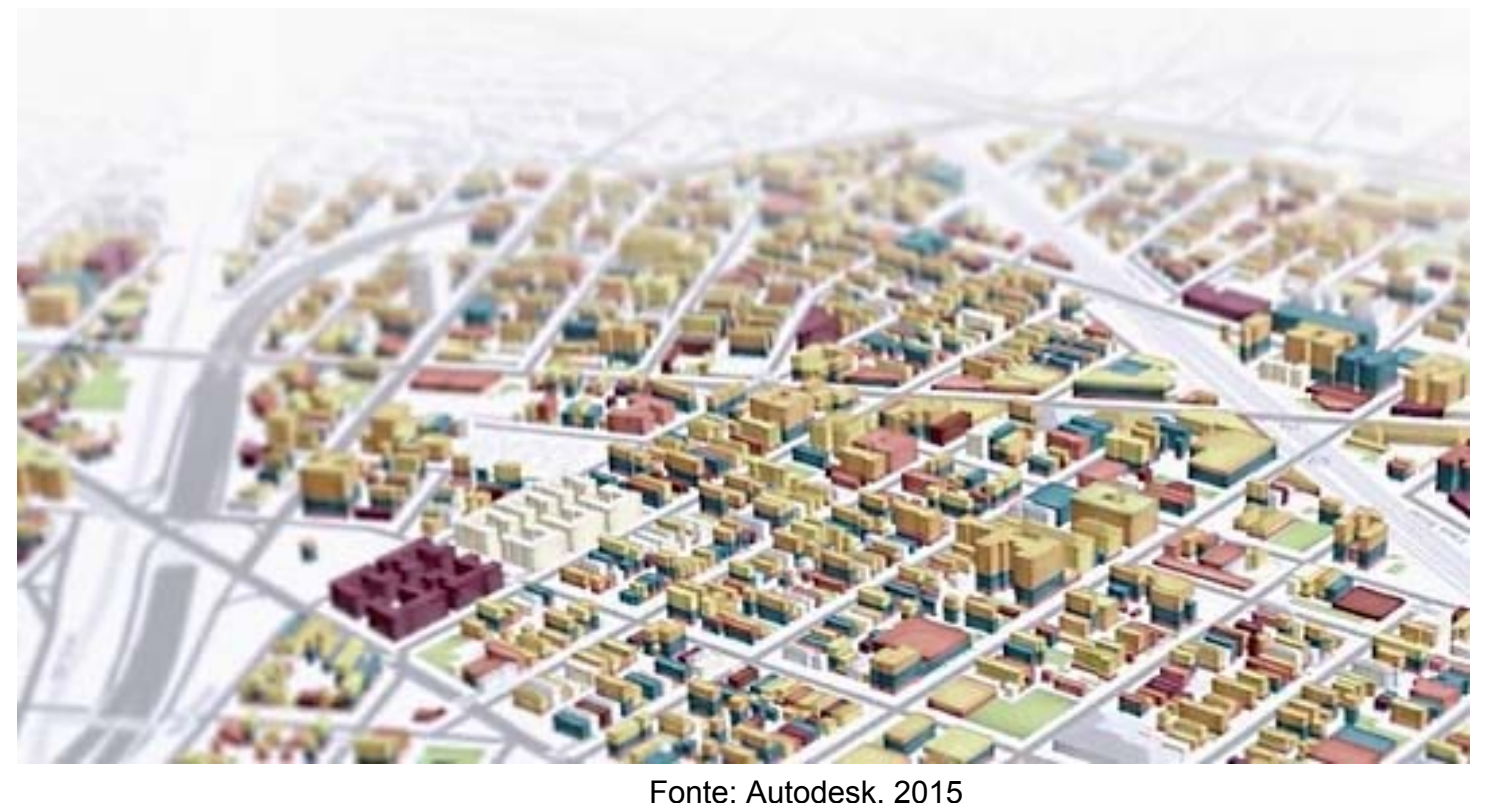

O software Urban Canvas funciona em integração com soluções Cloud, possuindo igualmente uma vertente desktop, pelo que aproveita as vantagens de ambas as facetas de desenvolvimento de projetos. Permite aos urbanistas editarem os dados do modelo diretamente na Cloud, com feedback visual em tempo real.

$\mathrm{O}$ quadro de modelagem urbana permite a rápida geração de modelos 3D de edifícios, incorporando funções que facilitam a geração automática de zonas metropolitanas com base em tipologias, restrições geométricas e funcionais, bem como em estilos arquitetônicos, entre outros fatores (Figura 6). Possibilita também o estudo de múltiplos cenários para a mesma área e confere uma quarta dimensão nos projetos ao permitir visualizar a evolução no tempo de diferentes propostas.

\subsection{Uma abordagem conceitual entre o desenvolvimento sustentável e o BIM}

A cada dia a população se concentra mais nas cidades e o mundo se torna mais urbano. Essas mesmas cidades consomem muita energia e respondem cada vez mais pelas emissões de CO2. Então, para que se verifique uma redução nas alterações climáticas, deve-se promover mudanças nas cidades (LEITE, 2012).

O conceito de desenvolvimento sustentável deve ser assimilado como uma nova forma de produzir sem degradar o meio ambiente, estendendo essa cultura a todos os níveis de organização, para que seja formalizado um processo de identificação do impacto da produção no meio ambiente e resulte na execução de um projeto que alie produção e preservação ambiental, com uso de tecnologia adaptada a esse preceito (BRUNDTLAND,1987).

Em muitos casos, o crescimento demográfico e a produção de novos espaços urbanos são acompanhados por uma segregação entre as questões urbanísticas e ambientais (Figura 7), tendo como consequências profundas lacunas no entendimento do espaço urbano como uma célula viva em constante transformação

A combinação de dados da cidade de Campos dos Goytacazes - RJ através de ferramentas BIM de visualização e simulação realista, permitirá aos gestores municipais visualizar e interagir com a paisagem da cidade, bem como para analisar os impactos de seu futuro planeamento urbano. 


\section{TIC2015}

Figura 7: Floresta $x$ cidade: 2 ecossistemas diferentes
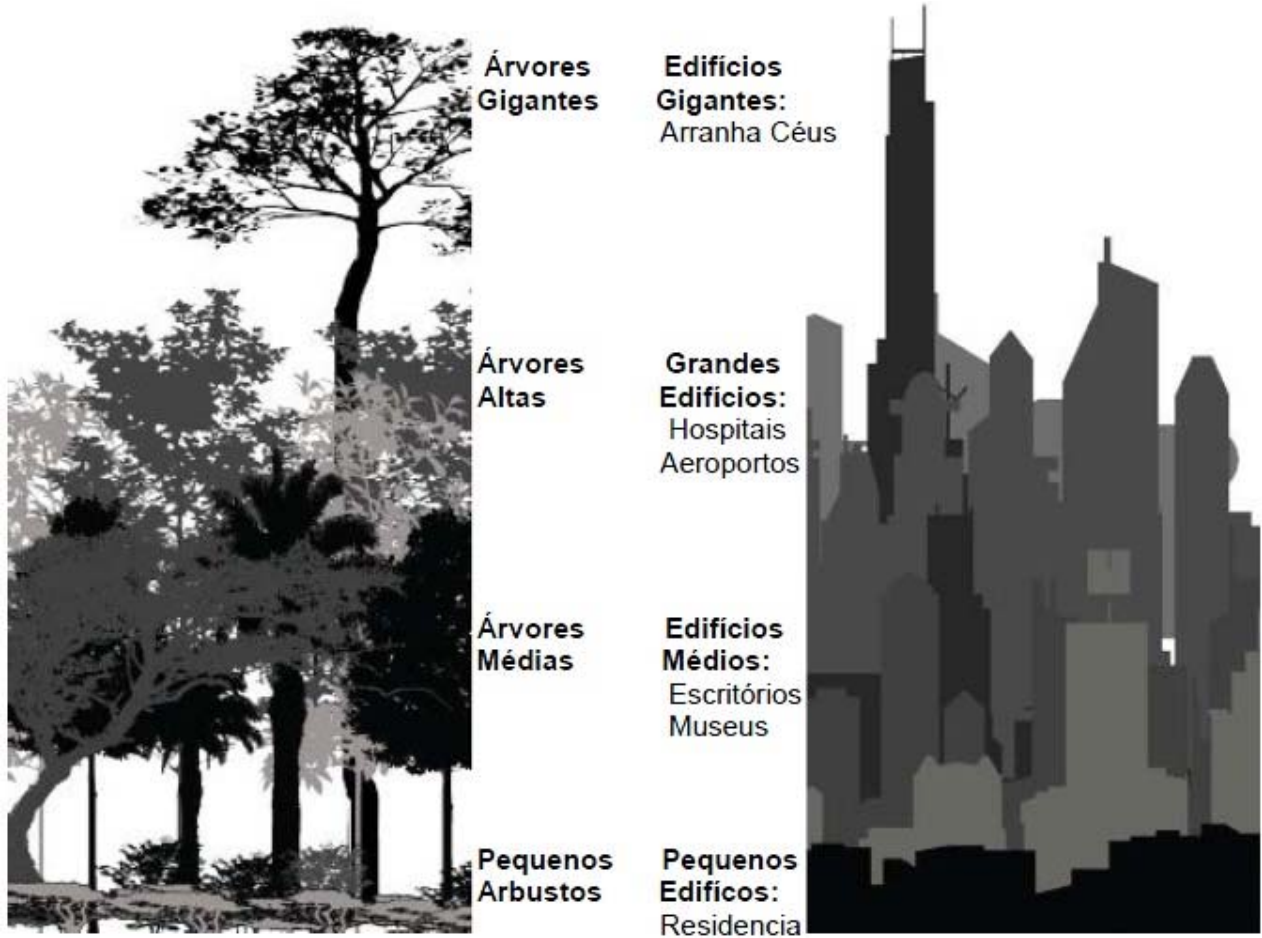

Fonte: Deerns, 2014

Os benefícios ambientais advindos do processo de urbanização sustentável são variados, influenciando não apenas o próprio ecossistema diretamente, mas também, as populações residentes nas cidades. Conforme a figura 8 , é possível entender de forma ilustrativa as possibilidades de compartilhamentos de recursos naturais vitais nas cidades.

Figura 8 - llustração entre a simbiose de objetos estáticos em um ambiente dinâmico

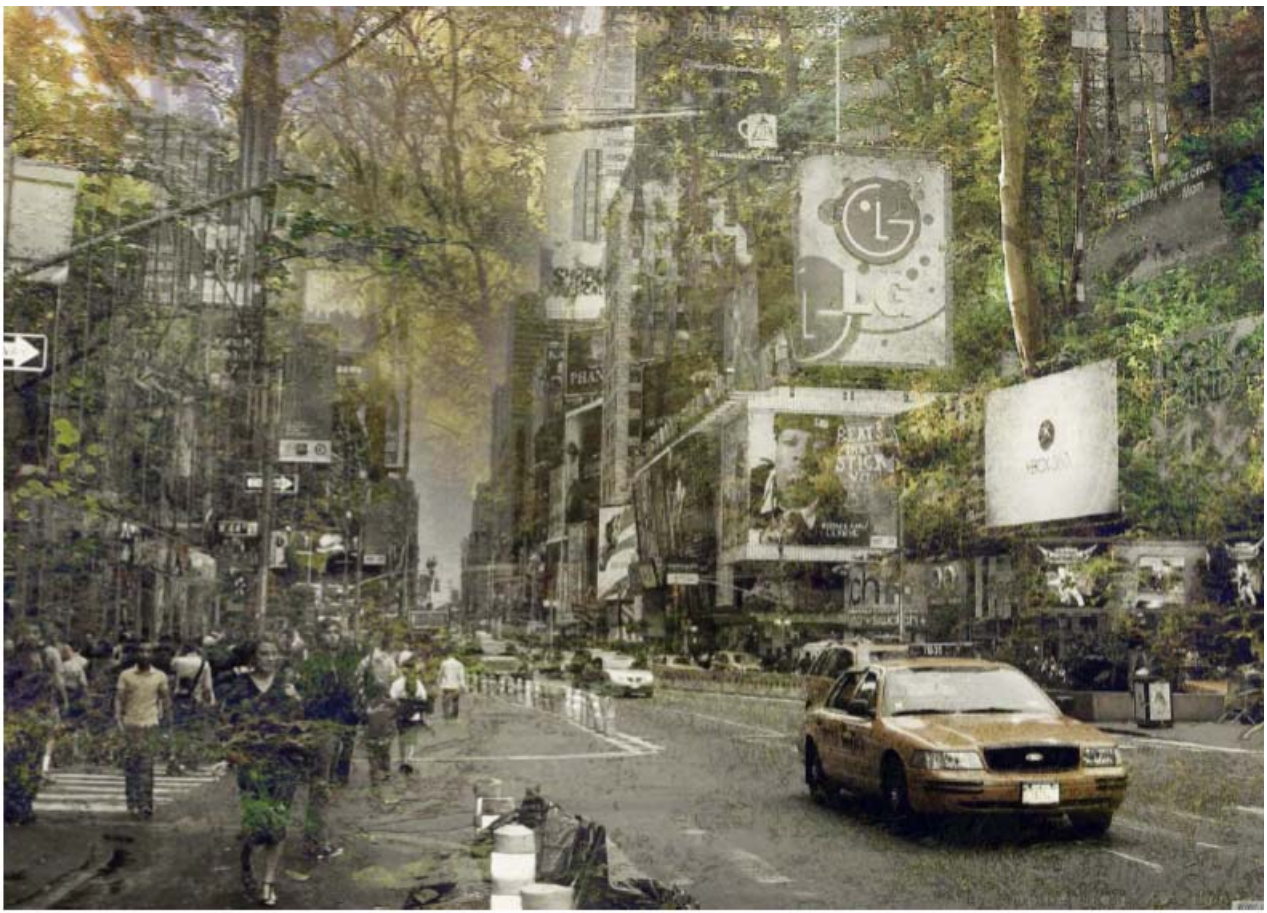

Fonte: Deerns, 2014 
O conceito BIM para elaboração de projeto abrange o processo de construção do modelo do edifício ou de um conjunto deles, atribuindo-lhe informações em várias dimensões (EASTMAN et al., 2008) O setor dimensional da plataforma BIM vai além das três dimensões do espaço (Figura 9). Assim como é usado para a obtenção de dados de custos e planejamento, especificações de materiais, elementos construtivos, e demais informações conforme a necessidade do projeto e nível de detalhamento, esta plataforma pode vir a ser útil também para mensurar o impacto ambiental das edificações em suas áreas de implantação, podendo ser aplicado a bairros e cidades.

Figura 9: BIM e suas dimensões

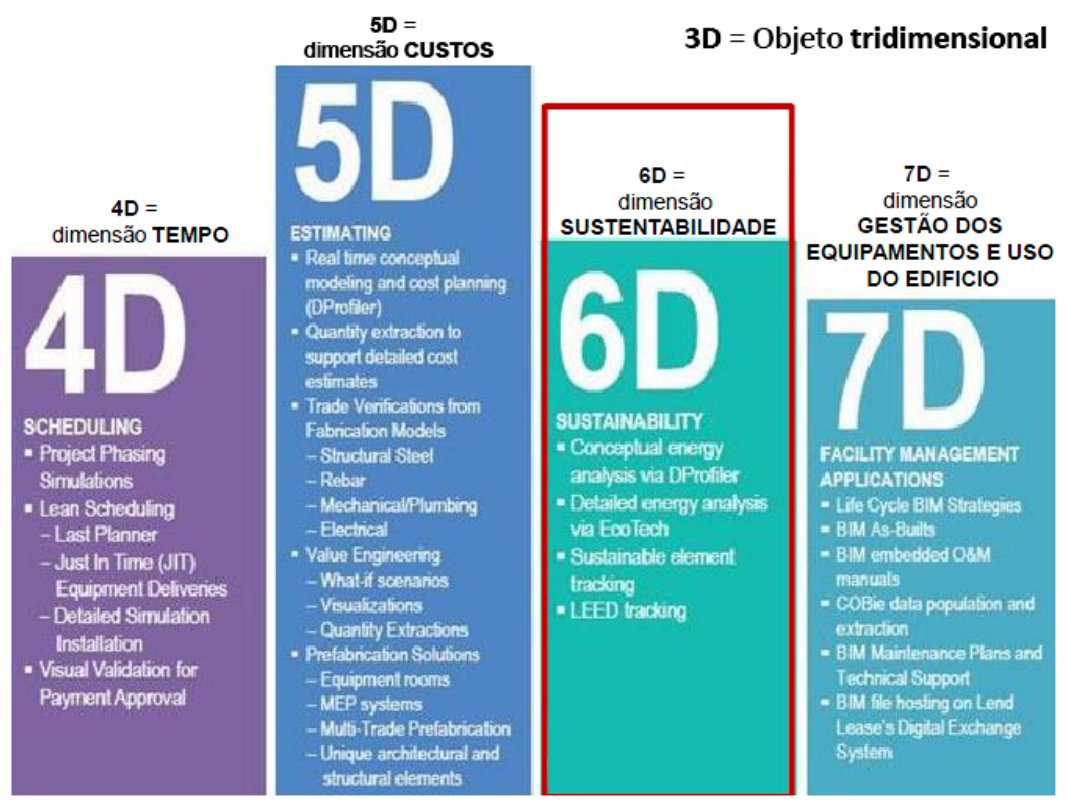

Fonte: Deerns, 2014

Os tomadores de decisões podem ver e compartilhar arquivos no início do ciclo de design, tornando o projeto sustentável mais eficiente e eficaz em termos de custos. A tecnologia é projetada para fornecer um ambiente colaborativo para visualizar, analisar e simular o impacto futuro do design urbano e desenvolvimento à escala de toda a cidade.

Os benefícios do uso de BIM para o Projeto Sustentável permitem que os arquitetos criem um modelo digital ou protótipo antes que a construção propriamente dita comece (Figura 10). Como tal, a utilização do BIM oferece vários benefícios ao se criar a concepção de construção sustentável (BUILDIPEDIA, 2013). A seguir estão as principais vantagens do uso do BIM para o projeto sustentável:

- Melhor tomada de decisão. Durante o processo de concepção dos projetos, os arquitetos devem considerar várias opções e ter informações suficientes para escolher uma. O BIM permite que os arquitetos criem e estudem várias opções dentro de um único modelo.

- Melhor análise de dados. Devido aos gráficos de alta resolução, qualidade dos detalhes e uma interface de modelagem 3D, o BIM ajuda a criar um modelo virtual preciso de um projeto de construção sustentável. Este modelo pode ser muito útil para fazer diferentes tipos de análise, como a quantificação e detecção de conflitos.

- Acesso mais fácil à informação. O uso de um modelo de projeto baseado em BIM garante que os arquitetos e projetista obtenham acesso fácil às informações necessárias para a criação de um projeto sustentável. 
- Simplifica a Certificação ambiental. Um modelo baseado em BIM inclui todas as informações necessárias para os vários aspectos de um projeto sustentável. Ele permite a criação de detalhes que melhoram a precisão da certificação verde.

Figura 10: Processo BIM na construção de territórios sustentáveis

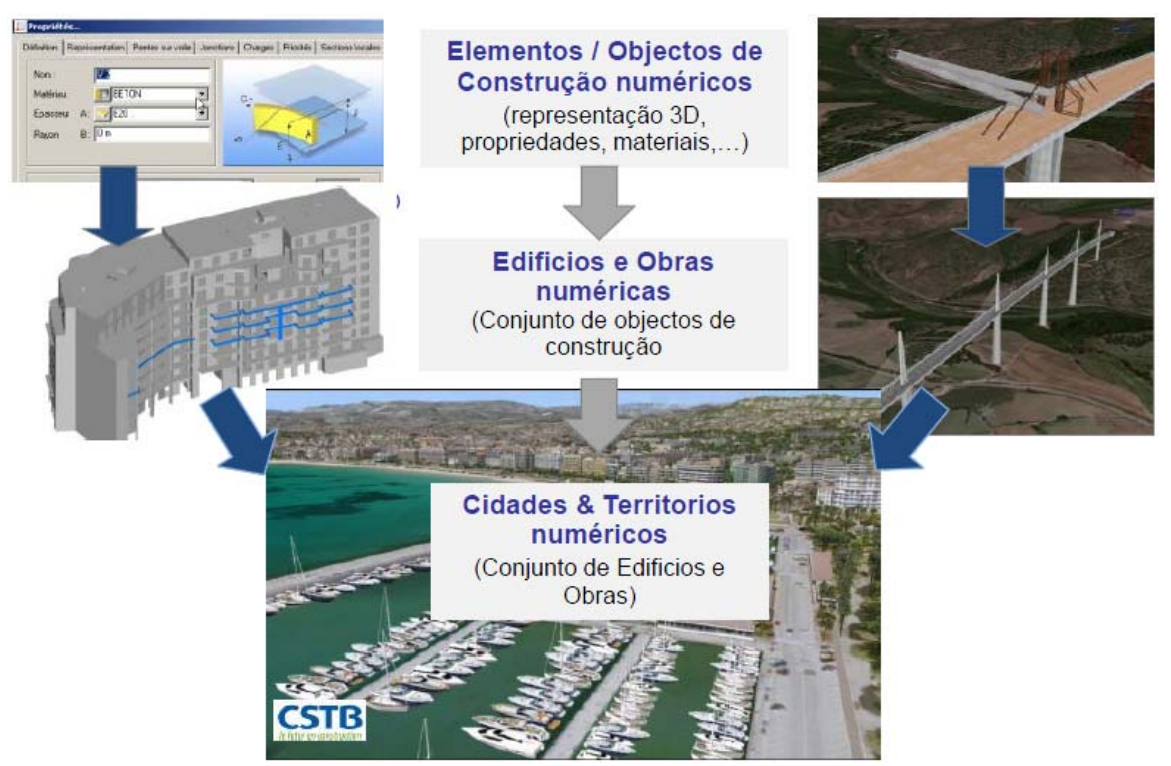

Fonte: Deerns, 2014

\section{RESULTADOS}

Este trabalho obteve como resultado parcial, referências do uso da plataforma BIM na gestão de territórios urbanos integrados e sustentáveis, colaborando, assim, com possíveis implementações destes resultados aos gestores públicos em Campos dos Goytacazes - RJ.

Neste sentido, os conhecimentos encontrados através da pesquisa bibliográfica e do estudo de caso, visam colaborar com o CIDAC, Centro de Informações e Dados de Campos, através das seguintes propostas:

- Fomentar a pesquisa e a capacitação de seus servidores (funcionários) e colaboradores (empresas privadas e/ou profissionais liberais ligados ao órgão municipal) acerca dos conceitos da plataforma BIM e do desenvolvimento sustentável;

- Aquisição de softwares BIM de visualização e simulação, específicos para o planejamento urbano;

- Promover a criação de bancos de dados interoperáveis nos demais órgãos municipais, como a Secretaria de Obras, Planejamento e Meio Ambiente;

- Analisar as interferências nas propostas BIM e as legislações vigentes do município, tendo como resultado possíveis revisões e modificações.

\section{CONCLUSÕES}

Este trabalho se baseia na pesquisa de novas metodologias e ferramentas de gestão e planejamento urbano no cenário mundial através da Plataforma BIM, a fim de propor aos gestores públicos da cidade de Campos dos Goytacazes - RJ alternativas eficazes para o desenvolvimento sustentável municipal, entendendo como sustentável "o desenvolvimento que satisfaz as necessidades do presente sem comprometer a capacidade das gerações futuras satisfazerem as suas próprias necessidades " Brundtland (1987). 
Diante do cenário de incertezas políticas e econômicas acerca da exploração e produção do petróleo, principal fonte de renda da cidade de Campos - RJ, este trabalho constatou, através do estudo de caso sobre evolução urbana do município, suas dificuldades em gerir as demandas crescentes de seu território urbano, submetendo o seu planejamento urbano aos altos e baixos da economia.

Por fim, este estudo resultou na pesquisa de referências do uso do BIM na gestão de territórios urbanos integrados e sustentáveis no cenário mundial, destinando estes resultados ao CIDAC, Centro de Informações e Dados de Campos, órgão municipal que analisará as propostas de melhoria em sua estrutura organizacional, a fim de servir como base em ações de implementação da plataforma BIM aos demais órgãos municipais responsáveis pelo planejamento urbano.

Estas propostas incluem o incentivo a pesquisa e capacitação a respeito dos conceitos BIM, aquisição de softwares específicos, criação de banco de dados interoperáveis aos demais órgãos municipais e análise das interferências destas ações. Nesse sentido, deve haver planejamento urbano a partir de uma lógica que pense de forma colaborativa e integrada na preservação dos recursos disponíveis e leve em consideração as futuras gerações.

\section{AGRADECIMENTOS}

Os autores registram seus agradecimentos à URFJ, pelo apoio ao projeto de mestrado do primeiro autor; ao CIDAC pela colaboração nas pesquisas concedidas ao primeiro autor; ao IFF, pelo apoio do projeto.

\section{REFERÊNCIAS}

BRUNDTLAND, G. H. (1987). World commission on environment and development Our common future (pp. 8-9).

BUILDIPEDIA. BIM and Sustainable Design. Disponível em: <http://buildipedia.com/aecpros/design-news/bim-and-sustainable-design>. Acesso em: 03 ago. 2015.

CIDAC - Centro de Informações e Dados de Campos. Disponível em:

<http://www.cidac.campos.rj.gov.br/index.php/menu-institucional/historia>. Acesso em: 30 jul. 2015.

EASTMAN, C.; TEICHOLZ, P.; SACKS, R.; LISTON, K. BIM Handbook: A guide to Building Information Modeling for Owners, Managers, Designers, Engineers, and Contractors. New Jersey: John Wiley \& Sons, Inc., 2008.

FARIA, T. de J. P. Campos dos Goytacazes. Resources et virtualités d'une ville brésilienne: données de I’historie. Tese de Doutorado, EHESS, Paris, França. 1998.

LEITE, C. Cidades Sustentáveis, Cidades Inteligentes: Desenvolvimento Sustentável num Planeta Urbano. Porto Alegre: Bookman, 2012.

LONDON, K., et al. Towards the Development of a Project Decision Support Framework for Adoption of an Integrated Building Information Model using a Model Server. Building Information Modeling and Construction Informatics. [s.n.], p. 270-300, 2010.

NBIMS - National Building Information Modeling Standard. Disponível em: <https://www.wbdg.org/pdfs/NBIMSv1_p1.pdf>. Acesso em: 30 jul. 2015.

ROSELAND, M. Dimensions of the eco-city, 1997.Disponível em:<http://raliberia.org/ ral/Dimensions\%20of\%20the\%20eco-city.pdf>. Acesso em: 14 out. 2012. 